\title{
Poesia de Anchieta: uma metodologia para análise do acento em textos antigos ${ }^{1}$
}

\author{
Anchieta poetry: an analysis method for the stress on an- \\ cient texts
}

Cristina Martins Fargetti ${ }^{2}$

Fernanda Regina Mistieri ${ }^{3}$

\begin{abstract}
Resumo: O presente artigo apresenta os resultados obtidos da análise do acento em Tupi Antigo utilizando-se como base o corpus de 10 poemas escritos em língua Tupi pelo jesuíta Pe. José de Anchieta. Para tal estudo foi desenvolvida uma metodologia nova, que visa facilitar a localização do acento em textos poéticos rigidamente metrificados. Este método mostrou-se eficaz não somente na análise do Tupi Antigo, mas também em estudos que levam em conta material escrito em forma de poesia, de épocas passadas, quando gravações sonoras ainda não existiam.
\end{abstract}

Palavras-chave: Métrica, Acento, Língua Tupi, Metodologia.

\begin{abstract}
This article presents the results of the analysis of stress in Ancient Tupi using the corpus of 10 poems written in Tupi by the Jesuit Fr. José de Anchieta. For this study it has been developed a new methodology, which aims to facilitate the location of stress in strictly metrical poetic texts. This method proved to be effective not only in the analysis of ancient Tupi, but also in studies that take into account written materials in the form of poetry, of a bygone era, when sound recordings did not exist.
\end{abstract}

Keywords: Metric, Stress, Tupi Language, Methodology.

\section{Introdução}

O Tupi Antigo, e/ou Tupinambá, foi amplamente falado em toda a costa brasileira por diversos grupos indígenas, tais como os Potiguara, os Caeté, os Tupinambá, os Temiminó, os Tabajara, entre diversos outros. Foi até o século XVIII utilizado como segunda língua por boa parte da população do Brasil - tanto por índios de outras etnias, negros ou europeus - caindo em declínio até praticamente desaparecer no século XIX, tendo ainda como variedade dele

\footnotetext{
${ }^{1}$ Texto em co-autoria.

${ }^{2}$ Livre Docente em Línguas Indígenas da UNESP - Faculdade de Ciências e Letras Araraquara - Departamento de Linguística, líder do Grupo LINBRA.

E-mail: cmfarget@gmail.com

${ }^{3}$ Mestre em Linguística da UNESP - Faculdade de Ciências e Letras - Araraquara Departamento de Linguística. E-mail: mistierifernanda@gmail.com
} 
derivada o Nheengatu, sobrevivente das Línguas Gerais. Foi pioneiramente descrito em uma gramática pelo jesuíta José de Anchieta, que também escreveu poemas, autos e produziu versões para a língua.

A língua foi certamente a mais estudada, no passado, dentre todas as línguas indígenas brasileiras. Falada em grande parte da costa até o século XVII, foi a primeira com a qual os colonizadores portugueses e jesuítas tiveram contato no país, tendo sido a base para, posteriormente, a formação das chamadas Línguas Gerais. Há controvérsias quanto ao que se denomina Tupi e Tupinambá, se ambas são línguas distintas ou se são dialetos de um mesmo idioma. Há duas correntes opostas nos estudos tupinológicos atualmente: a primeira - que tem como seu principal defensor Aryon Dall'Igna Rodrigues (1985) - afirma que o Tupi e o Tupinambá são duas línguas diferentes, sendo o Tupi restrito à antiga Capitania de São Vicente e o Tupinambá falado no restante do litoral. Essa tese baseia-se em algumas variações linguísticas registradas em gramáticas e textos antigos. Enquanto o Tupinambá mantinha a consoante final de verbos na forma afirmativa e utilizava o pronome objetivo i antes dos prefixos causativos mo- e seu alomorfe mbo- (voz causativa), o tupi não os possuía. Essa última diferença chegou a ser descrita por Anchieta. Por sua vez, a segunda teoria defendida por estudiosos como Navarro (2006) - sugere que Tupi e Tupinambá nada mais são que variedades de uma mesma língua, muitas vezes denominada de Tupi Antigo ou, simplesmente, Tupi. Para comprovar tal teoria, são levadas em consideração algumas observações: 1) Anchieta, Gândavo e outros autores reconheciam as diferenças dialetais, mas consideravam como pertencentes a uma mesma língua, tanto que Anchieta utilizou em seu Auto de São Lourenço as duas variedades simultaneamente; 2) As variedades não são suficientemente distintas para se cogitar a existência de dois idiomas diferentes.

Apesar de existir esta diferença de análise, ao dizermos, portanto, "Tupi Antigo", não estamos nos posicionando quanto a esta questão, uma vez que distinguir língua de variedade de língua, por vezes, aponta mais para um posicionamento de política linguística do que para fatores puramente formais, da estrutura da língua. Tratamos do Tupi descrito por Anchieta, e esta é uma limitação do nosso trabalho.

Considerando-se que, até então, poucas foram as línguas que receberam um estudo detalhado sobre o comportamento do acento, o objetivo da pesquisa apresentada em Mistieri (2013) foi estabelecer um estudo comparativo do acento em línguas da família Tupi-Guarani, utilizando como base teórica os modelos da fonologia métrica de Liberman e Prince (1977) e de Hayes (1995). Para o estudo em questão, foram selecionadas nove línguas de diferentes grupos e espaços geográficos: Avá-Canoeiro, Xetá, Nheengatu, Tupi Antigo, Guarani Mbya, Araweté, Tapieté, Asurini do Xingu e Kamaiurá. As análises individuais das línguas foram realizadas a partir de teses, dissertações, artigos e outros estudos acadêmicos anteriores de diferentes linguistas e estudiosos. De acordo com as 
informações contidas nesses trabalhos, foi traçada uma análise comparativa entre estas línguas, considerando as semelhanças e diferenças nas formas de manifestação dos padrões acentuais. Finalmente, foi averiguada a possibilidade de se estabelecer possíveis tendências ou semelhanças seguidas pelas línguas pertencentes à família com o objetivo de se buscar aspectos que possam remeter a características do Proto Tupi-Guarani. Neste artigo, nos limitamos a discutir o acento em Tupi Antigo, referenciando por vezes esse estudo mencionado, mas focalizando a metodologia empregada para uma análise de textos poéticos.

Este artigo tem a seguinte estrutura: primeiramente, apresentamos algumas considerações sobre a fundamentação teórica abordada; em seguida, a metodologia desenvolvida e adotada é discutida; passamos então a nossa proposta de análise, exemplificando o uso de tal metodologia e mostramos os usos que já teve em outro estudo.

\section{Fundamentação teórica}

\subsection{A Fonologia Métrica}

A Fonologia Gerativa Padrão de Chomsky e Halle via o acento apenas como uma propriedade - ou melhor, um traço distintivo ([ \pm acento $]$ ) - da vogal. Com o advento da Fonologia Métrica, o acento passou a ser considerado uma propriedade da sílaba, e não apenas de um segmento. Segundo Hayes "The central claim of theory, in my view, is that stress is the linguistic manifestation of rhythmic structure, and that the special phonological properties of stress can be explicated on this basis" (HAYES, 1995: 11). O acento pode ser visto como uma proeminência que nasce da relação entre os elementos prosódicos sílaba $(\sigma)$, pé $(\Sigma)$ e palavra fonológica $(\omega)$.

\subsection{A Sílaba}

Para se analisar o acento de forma eficiente é preciso adentrarmo-nos na estrutura silábica, e para isso faz-se necessária a utilização de uma teoria da sílaba - e neste caso, a teoria métrica da sílaba.

A sílaba foi muito valorizada no período da Antiguidade, porém passou por um grande período de esquecimento, reencontrando importância na Fonologia não linear, onde serviu como base para os estudos de ritmo, do pé métrico e do acento. Hooper (1976) e Kahn (1976) foram os pioneiros a apresentar a sílaba como uma unidade fonológica. Kahn (1976) considerava a existência de duas camadas independentes, sendo a primeira a camada da sílaba e, imediatamente inferior a esta e ligada diretamente, a camada dos segmentos.

Teorias não lineares passaram a considerar a sílaba como um componente fonológico por algumas razões, mais precisamente elencadas por Broselow (1996: 158-160): a) existência de processos ou restrições fonológicas que levam a sílaba como seu domínio de aplicação, tais como o acento e o tom. Estas 
regras e restrições são sensíveis a um domínio que é maior do que o segmento menor do que a palavra; b) existência de regras fonológicas que se aplicam nos limites da sílaba. Em todas as línguas, as bordas silábicas correspondem a bordas de palavras ou enunciados, e regras como a aspiração vocálica estão intimamente relacionadas aos limites silábicos. Limites que podem ser tanto o inicial (caso do Inglês, por exemplo) como o final (Maya Yucateco); c) o fato de a sílaba ser objeto de jogos de linguagem, como a conhecida "língua do P"; d) intuição e consciência do falante nativo da existência da sílaba.

Um dos primeiros trabalhos modernos relacionados à teoria métrica da sílaba foi a publicação de "On Stress and Linguistic Rhythm" (Liberman; Prince, 1977), e os trabalhos na área de fonologia que se seguiram (Selkirk, 1980; Hogg; Mccully, 1987; Goldsmith, 1990) buscaram sistematizar o funcionamento da estrutura interna da sílaba.

Nesta teoria, a sílaba $(\sigma)$ é constituída por um ataque (A) - podendo também ser chamado de Onset (O) - e por uma rima (R). A rima, por sua vez, é dividida entre Núcleo $(\mathrm{Nu})$ e Coda $(\mathrm{Co})$. Uma sílaba pode ser vazia em todas as características, com exceção do núcleo. Ou seja, uma sílaba deve conter ao menos uma vogal, podendo ou não ter onset e coda preenchidos, com ou sem ramificações.

\section{O corpus}

Dos 18 poemas que Anchieta compôs inteiramente em tupi antigo (de acordo com a classificação de Martins, 1954), dez deles foram selecionados para análise. A escolha seguiu critérios como o tamanho do poema (nem muito pequenos, nem muito extensos, para obter alguma uniformidade estrutural entre eles) e a regularidade da métrica (a fim de nos assegurarmos da regularidade do tratamento do acento).

Os poemas trabalhados foram os seguintes:

1. Cantiga por "o sem ventura"

2. Cantiga por querendo o alto Deus

3. Cantiga por 'El sin ventura'

4. Da assunção

5. Pitangĩ

6. Tupana kuápa

7. Trilogia

8. Dos Mistérios do Rosário de Nossa Senhora

9. Pitangi Porangeté

10. Dança 


\section{Metodologia}

O Tupi Antigo não dispõe de registros sonoros pelo fato de não ser mais falado há alguns séculos. Sendo assim, a única maneira possível de se estudar fenômenos prosódicos como a acentuação e o ritmo é através da metrificação e análise de textos poéticos antigos escritos pelo padre José de Anchieta em língua tupi, durante a segunda metade do século XVI. Considerando-se o fato de que a tradição poética desde a antiguidade até o século XIX era calcada na confecção de poemas sob uma métrica extremamente rígida, obras desse período podem vir a nos oferecer pistas que levem a uma possível caracterização da estrutura prosódica das palavras, como a localização do acento e o pé métrico básico da língua.

Como base para este estudo, foram utilizadas três edições da lírica anchietana publicadas em diferentes épocas (1954, 1984, 2004). O primeiro, de 1954, organizado pela professora Maria de Lourdes de Paula Martins, foi uma edição comemorativa lançada em homenagem aos 400 anos da cidade de São Paulo. O segundo livro, de 1984, foi organizado pelo tupinólogo Pe. Armando Cardoso, e o terceiro, de 2004, organizado pelo professor da USP de língua Tupi, Eduardo Navarro.

O método de Massini-Cagliari (1995) para análise do acento via métrica no Português Arcaico serviu como exemplo para as análises presentes neste trabalho, visto que a autora utiliza as teorias de Liberman e Prince (1977) e Hayes (1995) e as aplica a textos poéticos, com o objetivo de elucidar questões fonológicas. Em seu estudo, Massini-Cagliari (1995; 1999) aproveitou-se da métrica rígida das cantigas do patrimônio poético do português arcaico para analisar o acento e o ritmo na língua e a partir dos resultados, traçar um percurso histórico das possíveis mudanças de padrões acentuais do Português Arcaico ao português brasileiro dos dias de hoje.

Sobre esta metodologia, Massini-Cagliari defende:

Quando se tem como objetivo a investigação de elementos prosódicos - como, no caso, o acento - de um período de uma língua quando ainda não havia tecnologia suficiente para arquivamento e transmissão de dados orais, a possibilidade de escolha entre material poético e não-poético para a constituição de um corpus não se coloca. Como os textos remanescentes do PA são todos registrados com um sistema de escrita de base alfabética, sem qualquer tipo de notação especial para os fenômenos prosódicos, fica praticamente impossível de serem extraídas informações como as que estão sendo aqui buscadas, a respeito do acento e do ritmo do português desse período, a partir de textos escritos em prosa. Já em relação a textos poéticos, ocorre o contrário, principalmente se estes forem metrificados, isto é, se levarem em conta o número de sílabas e/ou a localização dos acentos 
em cada verso, podem ser inferidos os padrões acentuais e rítmicos da língua na qual os poemas foram compostos. Da localização dos acentos poéticos, pode-se concluir a localização do acento nas palavras, ou seja, os padrões de acento lexical da língua, e, da concatenação desses acentos dentro dos limites de cada verso, os padrões rítmicos da língua em questão. (Massini-Cagliari, 1999: 27)

Para os fins desta pesquisa, o enfoque será dado especialmente à palavra localizada na posição final do verso, onde se estabelecem as rimas poéticas. Segundo Costa, que adota metodologia de Massini-Cagliari (1995):

Essa posição é privilegiada na metodologia pelo fato de se poder estabelecer com segurança, devido à contagem das sílabas poéticas [...] se a palavra, na posição da rima é oxítona, paroxítona, proparoxítona ou se se trata de um monossílabo. (Costa, 2006: 72-73)

Em uma língua sem registros sonoros e de tendência aglutinante, com uma enorme gama de afixos, em que não é possível se obter com segurança o domínio total de suas estruturas por parte de estudiosos, a precaução de se estabelecer o enfoque nas palavras em posição final faz-se a melhor opção.

Observando as palavras em finais de versos é possível descobrir, pela rima, a localização da sílaba tônica na palavra. Como ilustração, é apresentada abaixo uma quadra do poema "Dos mistérios do rosário de Nossa Senhora" de autoria do Padre José de Anchieta:

Nde mbya pupe

Pitangamo oupa

Tupana rerupa

Ipo nde ryge

A quadra possui rimas interpoladas (mais especificamente, o sistema ABBA) alternando entre versos agudos (oxítonos) e graves (paroxítonos). . O $1^{\circ}$ e o $4^{\circ}$ versos são agudos, pois rimam somente na coda da última sílaba ('e').

Já o $2^{\circ}$ e $3^{\circ}$ versos são graves, pois a rima engloba toda a sílaba final -ataque (p) e rima (a) -mais o núcleo da sílaba anterior

De acordo com a representação, é possível ver a diferença na rima entre palavras oxítonas e paroxítonas: 


\section{Oxítonas (palavras"pupe" e "rige")}

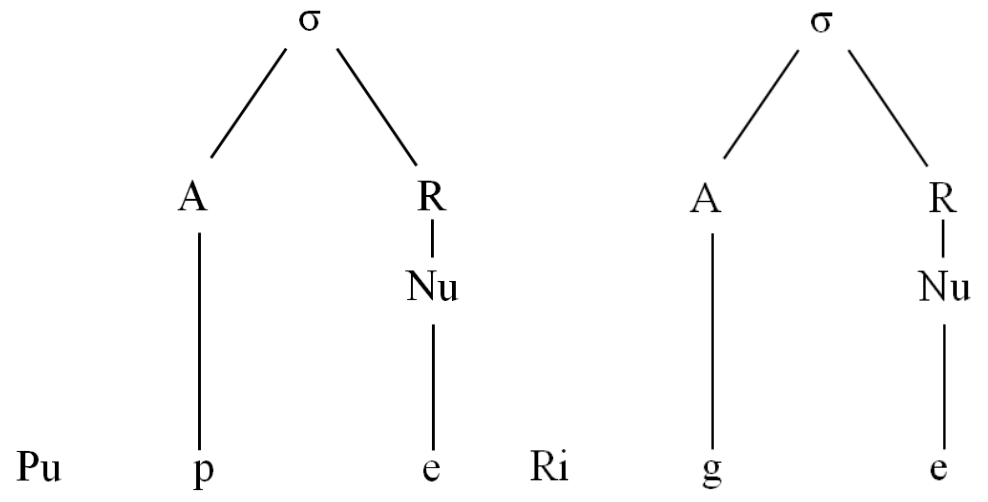

Paroxítonas ("oupa" e "rerupa"):

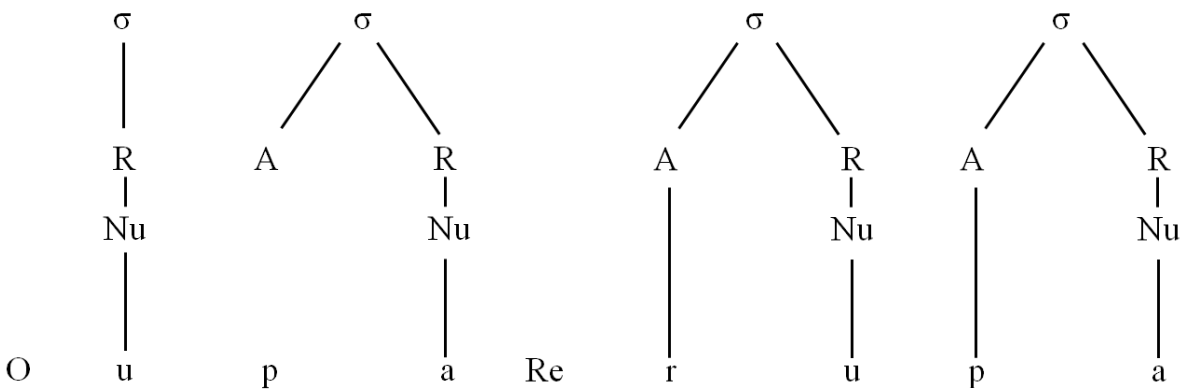

\subsection{Os Versos-Chave}

Este desdobramento metodológico, proposto pioneiramente por Mistieri (2010), sustenta que, em uma língua cujo estudioso não tenha o domínio pleno de sua estrutura e dinâmica, o processo de escansão de um poema deve ser iniciado a partir de um ou mais versos-chave.

Definimos um verso-chave como aquele em que sua estrutura é preferencialmente constituída por sílabas CV (consoante-vogal), V (vogal), CVC (consoante-vogal-consoante), ou verso no qual não ocorra nem um tipo de ditongação ou encontro vocálico, fazendo assim com que não haja dúvidas quanto a sua divisão silábica, além de servir como parâmetro para a escanção dos demais versos.

Neste poema utilizamos o verso-chave "Tupana rerupa" escandido da seguinte maneira: Tu / pa / na / re / rú / pa. Nota-se que este verso não possui ditongos ou qualquer tipo de encontro vocálico. A partir desse verso-chave e do esquema de rimas podemos concluir que os versos dividem-se da seguinte maneira: 
nde y / by / ia / pu / pé /

pi / tan / ga / mo o / ú / pa

$\mathrm{Tu} / \mathrm{pa} / \mathrm{na} / \mathrm{re} / \mathrm{rú} / \mathrm{pa}$

I / po n / de / ry / gé /
5 SÍLABAS

5 SÍLABAS

5 SÍLABAS

5 SÍLABAS

O uso desta técnica aplicada à escansão de poemas em língua Tupi se faz pertinente, já que nesta língua há grande ocorrência de sílabas $\mathrm{CV}, \mathrm{V}$ e CVC.

Infelizmente, esse método não pode dividir com precisão as sílabas em meio de verso, quando se trata de ditongos, tritongos ou hiatos, podendo criar uma divisão ambígua nesses casos, mas como o foco deste trabalho está nas sílabas em final de verso - que não permitem tal ambiguidade - não iremos nos ater a esses casos.

As constatações sobre o acento obtidas através dessas escansões foram comparadas aos estudos já realizados sobre a acentuação em Tupi, como nas gramáticas de Anchieta (1990) e de Lemos Barbosa (1956), a fim de verificar se, em seus poemas, o jesuíta respeitou as regras de acento (também descritas por ele anteriormente), adaptando a métrica à língua, ou se há incoerências entre a incidência da sílaba tônica nas palavras analisadas em sua lírica em relação àquilo que está descrito nas gramáticas, adaptando a língua à métrica.

\section{Análise dos poemas}

\section{Cantiga por "o sem ventura"}

Como anteriormente exemplificado, com a observação das palavras em finais de versos dá para se descobrir pela rima a localização da sílaba tônica na palavra:

Tupansy porangeté

Oropab oromanómo

Ore moingobe jepé

Nde membyra monhyrómo

Inongatuábo

Ore rarómo

Ore anga pysyrómo

Este trecho do poema possui rimas misturadas (no caso desta estrofe, em sistema $\mathrm{ABABCBB}$ ) alternando entre versos graves (paroxítonos) e agudos (oxítonos).

As partes em negrito rimam entre si. $\mathrm{O} 1^{\circ}$ e o $3^{\circ}$ versos podem ser considerados agudos pois rimam somente o núcleo da última sílaba (e). Já o $2^{\circ}, 4^{\circ}, 6^{\circ}$ e $7^{\circ}$ versos são graves pois a rima engloba toda a sílaba final - tanto o ataque (m) quanto a rima (o) - mais o núcleo da sílaba anterior.

Através da representação a seguir, é possível ver a diferença na rima entre palavras oxítonas e paroxítonas: 


\section{Oxítonas (palavras "porangeté" e "jepé")}
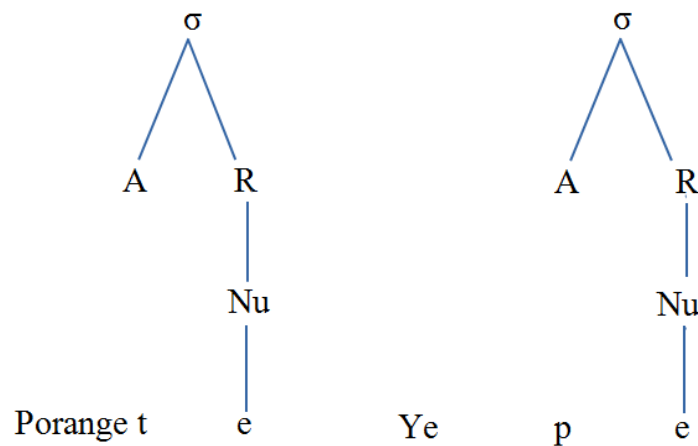

\section{Paroxítonas ("Oromanomo" e "monhyromo", por exemplo)}

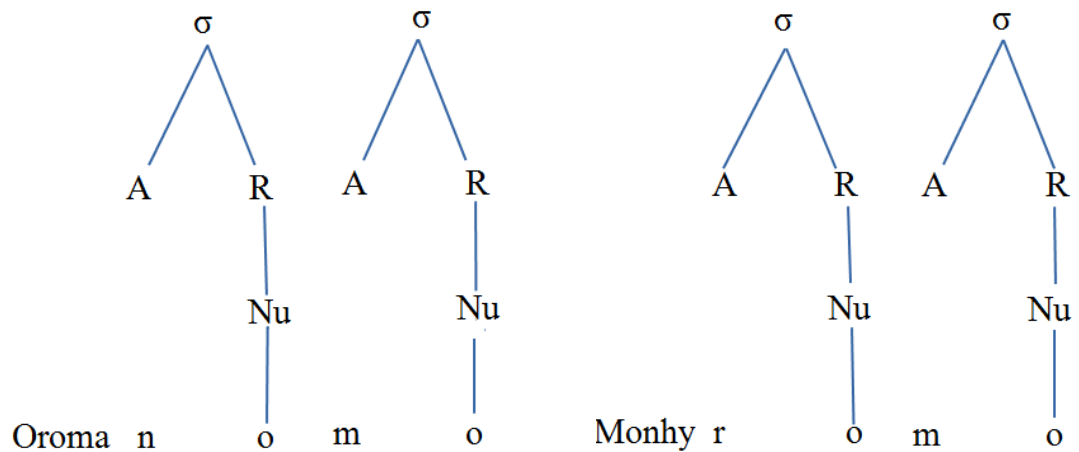

A escansão deste poema tomou por base os seguintes versos-chave:

Tupansy porangeté ( $\mathrm{Tu} / \mathrm{pan} / \mathrm{sy} / \mathrm{po} / \mathrm{ran} / \mathrm{ge} /$ te ) - 7 SílABAS

Oropab oromanómo $(\mathrm{O} / \mathrm{ro} / \mathrm{pa} / \mathrm{b}$ o / ro / ma / no / mo $)$ - 7 SÍLABAS

Nde membyra monhyrómo (Nde/mem/by/ra/mo/nhy/ro/mo) - 7 SÍLABAS

Nde membyra mongetábo (Nde/mem/by/ra/mon/ge/ta/bo) - 7 SílABAS

Imomoséma (I / mo / mo / se / ma) - 4 SÍLABAS

Nde rapekóbo (Nde / ra / pe / ko / bo) - 4 SÍLABAS

Nde su nde súpa (Nde / su n / de / su / pa) - 4 SÍlABAS

Com a ajuda destes versos, também foi possível descobrir que as estrofes -de sete versos (heptetos) - estão estruturadas em: um primeiro grupo de quatro versos com sete sílabas cada; dois versos de quatro sílabas; e um verso final também de sete sílabas.

Tupansy porangeté 7

Oropab oromanómo 7

Ore moingobe jepé 7

Nde membyra monhyrómo 7

Inongatuábo 4 
Ore rarómo 4

Ore anga pysyrómo 7

\section{Cantiga por querendo o alto Deus}

Pelo verso "pitang amongatu seko potári” (pi / tan / g a / mon / ga / tu / se / ko

/ po / ta / ri) é possível se concluir que se trata de um poema decassílabo.

Através das rimas se identifica que este poema possui somente versos graves (paroxítonos)

\section{Cantiga por 'El sin ventura'}

É possível perceber a semelhança estrutural entre esse poema e a "Cantiga por 'O sem ventura' à Nossa Senhora”: em ambos as estrofes são constituídas por sete versos, sendo os quatro primeiros heptassílabos, os dois seguintes de quatro sílabas, e, por último novamente uma redondilha maior. Esse poema também é marcado pela grande incidência de paroxítonas em posição de rima no verso. Os versos-chave para a escansão deste poema foram:

“jande rarómo " (Jan / de / ra / ró / mo) - 4 sílabas

"Asopota nde retáme"(A / so / po / ta / nde / re / tá / me) - 7 sílabas

"nde koty xererobáka" (nde / ko / ty / xe / re / ro / bá / ka) - 7 sílabas

\section{Da Assunção}

Essa cantiga possui uma grande quantidade de versos-chave, tornando sua metrificação mais fácil de ser realizada:

Ara angaturameté (A / ra an / ga / tu / ra / me / té /) 7 SílABAS

Nde membyra rorypápe (Nde / mem / by / ra / ro / ry / pá / pe) 7 SÍLABAS

Nde rese serokipyra (Nde / re / se / se / ro / ki / py / ra) 7 SÍLABAS

Nde reko poranga ri (Nde / re / ko / po / ran / ga / ri /) 7 SíLABAS

nde rekokatu pupé! (Nde / re / ko / ka / tu / pu / pé /) 7 SílABAS

tasone nde ropesýka (Ta / so / ne $\mathrm{n} / \mathrm{de} / \mathrm{ro} / \mathrm{pe} / \mathrm{sý} / \mathrm{ka}$ ) 7 SÍLABAS

\section{Pitangĩ}

A partir dos versos-chave abaixo, é possível verificar que o poema é, mais uma vez, construído em cima de versos heptassílabos:

nde rekokatu pupé (Nde / re / ko / ka / tu / pu / pé /) 7 SílLABAS Nasopotari mamõ (Na / so / po / ta / ri / ma / mõ /) 7 SÍLABAS xe anga pupe serúpa (xe / na / ga / py / sy / ron / sá / pe) 7 SílABAS ybate xe rerasóbo (Y / ba / te / xe / re / ra / só / bo) 7 SílABAS Nde rekokatu potá (Nde / re / ko / ka / tu / po / tá /) 7 SÍLABAS Iporangatu nde réra(I / po / ran / ga / tu n / de / ré / ra) 7 SÍLABAS 
Nesta cantiga pode-se notar casos de queda da consoante final nas palavras em posição de rima, como tereju(r), rimando com jakatú.

No verso "Oroausub katu guitekóbo" (O / ro / au / su(b) / ka / tu / gui / te / kó / bo) há uma quebra da métrica - até então todos os versos eram heptassílabos com a presença de um verso eneassílabo. A ocorrência desse verso pode indicar que Anchieta preferiria quebrar a métrica a alterar a estrutura da língua ou o sentido do verso.

\section{Tupana kuápa}

Este poema foi construído em cima de versos pentassílabos e possui os seguintes versos-chave:

opa amokanhẽ (O / pa a / mo / ka / nhẽ /) 5 SÍlABAS

Pitangamo séni $(\mathrm{Pi} / \tan / \mathrm{ga} / \mathrm{mo} /$ sé /ni ) 5 SÍlABAS

\section{Trilogia}

Este poema também se trata de um heptassílabo e tem esses cinco versoschave para escansão:

Iporangatu resé (I / po / ran / ga / tu / re / sé / ) 7 SÍLABAS Arobykatupeká (A / ro / by / ka / tu / pe / ká / ) 7 SÍlABAS Tupansy porangeté $(\mathrm{Tu} / \mathrm{pan} / \mathrm{sy} / \mathrm{po} / \mathrm{ran} / \mathrm{ge} /$ té / ) 7 SíLABAS Rerytyba, xe retáma (Re / ry / ty / ba / xe / re / tá / ma ) 7 SÍLABAS Santa Maria Supé (San / ta / Ma / ri / a / su / pé / ) 7 SÍlABAS

\section{Dos Mistérios do Rosário de Nossa Senhora}

Este poema possui uma grande quantidade de versos-chave, o que nos permite, com segurança, afirmar que se trata de outro poema pentassílabo.

(Tu / pa / na / re / rú / pa) 5 SílABAS

(nde / mem / by / ra / sá / pe ) 5 SílABAS

(nde / ka / ma / pu / pé /) 5 SÍlABAS

( $\mathrm{Pi} /$ tan / ga / ro / bá /) 5 SílABAS

(O / so / ku / nu / mi /) 5 SÍLABAS

(O / gu / ba / re / sé /) 5 SÍlABAS

( $\mathrm{Mi} / \mathrm{ty} / \mathrm{ma} / \mathrm{pu} / \mathrm{pé} /$ ) 5 SÍlABAS

(Nde / re / sa / pe / nhe / ) 5 SÍlABAS

(Y / py / re / ce / bé /) 5 SÍLABAS

(A / nhan / ga / ndi / bé /) 5 SÍLABAS

(Y / ba / ka / ra / sá / pa) 5 SÍLABAS

(O / sy / k o / re / ri /) 5 SÍLABAS

(Tu / pã / tu / ba / pý / ri) 5 SÍLABAS

(O / re / su / ma / rã /) 5 SÍlABAS 


\section{Pitangĩ Porangeté}

Em mais um poema heptassílabo, os seguintes versos-chave foram selecionados:

(Pi / tan / gi / po / ran / ge / té /)7 SÍLABAS

(Ko / xe / an / ga / nde / ru / sá / ba,) 7 SílABAS

$(\mathrm{O} / \mathrm{ré} / \mathrm{mo} / \mathrm{ka} / \mathrm{nhe} / \mathrm{me} /$ té /) 7 SílABAS

(A / nhan / ga / ra / ta / pe / nhe /) 7 SílABAS

(Te / ko / po / xy / mo / mo / rán / ga) 7 SílABAS

(Ta / xe / mo / mo / ta / re / té /) 7 SílABAS

(Nde / ro / ba / po / ran / ga / tú /) 7 SílABAS

(O / pa / bi n / de / mo / mo / rán / ga) 7 SílABAS

(Nde / re / ra / ren / du / pa / be /) 7 SílABAS

(Nde / re / ko / ka / tu / ru / pi /) 7 SílABAS

(Pe / ca / do / mo / nhan / gi / ré /) 7 SÍLABAS

\section{Dança}

Este poema também é formado de versos heptassílabos e possui os seguintes versos-chave:

(Tu / pã / py / ri / to / ro / só /) 7 SílABAS

(Nde / re / ra / ren / du / pa / be / ) 7 SílABAS

(Ko / ta / ba / Tu / pã / re / sé /) 7 SÍlABAS

$(\mathrm{O} / \mathrm{re} / \mathrm{py} / \mathrm{ri} /$ te / re / rú /) 7 SÍlABAS

\section{O que estudiosos dizem sobre o acento em tupi}

Anchieta (1990 [1595]) descreve que o acento no Tupi Antigo poderia variar conforme a estrutura morfológica da palavra, embora por padrão, a língua teria como base palavras oxítonas. Anchieta, porém, não especifica quais são os condicionamentos morfológicos do acento em Tupi. Anchieta faz os seguintes apontamentos sobre o acento na língua:

Todas as dicções acabadas nas quatro últimas vogais $i, o, u, y$ têm o acento na última e notam-se com o acento agudo ou com til, se são nasais. Algumas acabadas em $e$, que parecem ter o acento na penúltima, é por serem compostas, como ikatúpe nu (de i-katú-pe), ñote só (ñó-te); o-eté-pe em seu corpo. As acabadas em a, algumas têm o acento agudo na última, como tatá fogo; outras na penúltima, como óka casa. Os monossílabos, se são pronomes pessoais ou prefixos verbais ou sufixos enclíticos, não se acentuam, como acima o-eté-pe; os outros melhor se acentuam com o agudo ou til, como ñó só, $\tilde{n} u$ campo etc. Os verbos, pela maior parte, têm o acento na última, em qualquer consoante ou vogal que acabem, como ajuká eu mato, 
amondéb eu meto etc. Os mais acabados em $i$, precedendo vogal, têm o acento na penúltima ou se hão de chamar contratos ou ditongos, como akái eu ardo, ajuséi eu desejo comer, beber. Alguns poucos há acabados em $u$, precedendo vogal, têm o acento na penúltima, como estes passados (contratos ou ditongos), comumente, derivam de outras dicções, como a-i-mo-ngaráu eu o desconjunto, xe éu eu arroto.

(ANCHIETA, 1990 [1595], 154-5)

Cardoso, em adendo à edição d'Arte de gramática da língua mais usada na costa do Brasil (in Anchieta, 1990 [1595], p.155) apresenta os seguintes sufixos como átonos (palavras com essas terminações seriam, necessariamente, paroxítonas ou proparoxítonas): $m a, b a$, bae, ne, $a, i, u$ oui, pe, be, me, bo, pe, reme ou neme ou eme ou e, bo ou mo, te, ramo ou namo ou amo ou mo. $\mathrm{O}$ estudioso apresenta, também, prefixos que se unem a vocábulos sem que se altere o padrão acentual da palavra. Seriam esses prefixos: mo-, ro- ou no-, por(o)- ou po- ou mo- ou mbor(o)-, te- ou $t$-, s-e ou s-, a-, gui-, ere-, e-, oro-, ja- ou $n h a-$, pe-, opo-, i-, ij-, j-, inh-, $n h-, s_{-}, t-$, ia-, jo- ou nho-, jos- ou nhos-, o-, ogu-, og-, gu-, g-, gue-, je- ou nhe-, mi- ou mbi-, re- ou r-, nda-, nd-, na-, n-, ta-, $t$-.

Em capítulo dedicado ao acento no Curso de Tupi Antigo, Lemos Barbosa (1956, p.33) determina algumas regras para a localização do acento tônico: no caso de palavras terminadas em a) consoante; b) $y$; c) vogal nasal; d) ditongo crescente; e) $a, e, i, o, u$ (desde que pertencentes ao radical da palavra) são oxítonas. Há, porém, algumas partículas e sufixos enclíticos terminados em a, $e$, $i$, о ои $u$. Foneticamente formam uma só palavra com o vocábulo anterior. Seriam essas partículas, segundo o próprio autor, o $-a,-e,-i,-u,-p e,-m e,-b e$, -te, -ne, -mo, -bo, -no, -reme, -ramo, entre outras.

Em Phonologie der Tupinambá-Sprache, Aryon Dall'Igna, Rodrigues (1958, p.83) reserva um trecho de sua tese para a descrição do acento na língua, onde o linguista também discorre sobre a questão da sufixação de palavras :

A intensidade do acento pode aparecer na última, penúltima ou antepenúltima sílaba de uma palavra. Além disso, várias sílabas das palavras podem trazer o acento. [...] Toda palavra terminada em consoante tem acento na última sílaba. Apenas palavras terminadas em vogal podem tê-lo em uma das três últimas sílabas. Destas, pois, apenas através de sufixos de palavras derivadas, o acento se mostra na penúltima ou antepenúltima silaba. Palavras sem sufixo são, como toda raiz despida, acentuadas na última sílaba. A acentuação na penúltima ou antepenúltima sílaba depende, portanto, disso: o sufixo átono mono ou polissílabo segue a raiz da palavra. Por outro lado [...] a palavra carrega vários acentos quando é composta ou derivada de 
sufixos tônicos, nos quais cada acento corresponde a um membro da composição. Diante desta situação, produz-se como resultado que o comportamento dos acentos leva em consideração o ponto de vista morfológico. (RODRIGUES, 1958: 83) ${ }^{4}$.

\section{Nossa proposta de análise do acento em tupi}

O fato de todos os estudiosos apontarem que o algoritmo de atribuição do acento em Tupi obedece, primeiramente, a regras de caráter morfológico nos impossibilita afirmar que a língua possua acento rítmico. Todas as provas levam a se considerar esta língua como possuidora de acento morfológico e semifixo, pois sua localização é previsível e delimitável através de regras. A aparente diversidade posicional do acento acontece devido ao fenômeno da acentuação ocorrer no domínio do radical e não no da palavra. Sendo assim, as evidências apontam que o acento em Tupi é um fenômeno de aplicação lexical, pois é sensível às informações morfológicas; suas regras não se aplicam entre palavras; está intimamente relacionado à estrutura interna da palavra; e pode possuir exceções. Uma exceção à regra de aplicação do acento (lexical) está nos sufixos tônicos que alteram a pauta acentual da palavra, como podemos observar nos exemplos abaixo:

(a) Porang

po rang

'bonito/-a'

(. *)

(b) Porang-a

po ran ga

'bonito/-a' + nom.

$(. \quad *)$

\footnotetext{
${ }^{4}$ Original, em alemão: "Der Intensitätsakzent kann auf der letzten, vorletzeten oder drittletzeten Silbe eines Wortes auftreten (3.2.1.5.). Ausserdem können mehrere Silben eines Wortes des Akzent tregen (3.2.1.7.). Den in 3.2.1.5. Gesagten mus saber hinzugefügt werden, dass alle auf Konsonant endenden Wörter den Akzent auf der letzen Silbe haben. Nur vokalisch auslautende Wörter Können ihn auf einer der drei letzen Silben haben. Von diesen aber nur durch Suffixe abgeleitete Wörter weisen den Akzent auf der vor- oder drittletzten Silbe auf. Wörter ohne Suffixe sind, wie jeder blosse Stamm, auf der letzten Silbe betont. Die Betonung auf der von- oder drittletzten Silbe hängt also davon ab, ob dem Wortstemm ein einder mehrsilbiges inbetontes Suffix folgt. Andererseits, wie in 3.2.1.7. gesehen, trägt ein Wort mehrere Akzente, Wenn es zusammengesetzt oder durch betonte Suffixe abfeleitet ist, wobei jeder Akzent einem Glied des Kompositums entspricht. Aus dieser Situation ergibt sich, dass das Auftreten des Akzents von einem morphologischen Standpunkt aus prädiktabel ist”.
} 
(c) Porang-eté

po ran ge té

'muito bonito/-a'

$\left({ }^{*}{ }^{*}\right)\left(. \quad{ }^{*}\right)$

Em (a) temos porang, radical cuja última sílaba é acentuada. Em (b) temos o radical mais o sufixo nominalizador átono $\{-\mathrm{a}\}$ : a adição desse sufixo não alterou a posição do acento na língua, o que nos permite considerar que a nova sílaba $g a$ formada ao final seja extramétrica. Temos, neste exemplo, um processo típico que se enquadra no domínio lexical.

Já em (c) vemos uma exceção à regra de aplicação do acento: com a adição de um sufixo tônico, o acento principal migra para as margens da palavra, embora a sílaba ran ainda permaneça como a cabeça do pé métrico fraco (acento secundário). Como anteriormente apresentado, são previstas exceções para regras cujo domínio de aplicação se encontre no léxico.

A partir destas constatações, é possível se concluir que o Tupi é uma língua de ritmo iâmbico $\left({ }^{*}\right)$, visto que a regra geral é a acentuação na última sílaba do radical. Casos de incidência do acento na última sílaba da palavra devido a sufixo tônico só reforçam a tese de que a língua tem preferência pela proeminência final. As aparentes formas trocaicas que surgem em fator das ocorrências de paroxítonas, proparoxítonas e pré-proparoxítonas devido à inserção de sufixos átonos podem ser explicadas pela regra da extrametricidade: essas vogais, sílabas ou morfemas postônicos são desconsiderados por não terem participação no algoritmo de atribuição do acento.

Sendo assim, as palavras apresentadas por Barbosa (1956: 33) teriam a seguinte estrutura métrica:

Mo ru bi xa ba-pe

$\left({ }^{*}\right)$

Îu ká -re me

$\left(.{ }^{*}\right)$

Sy-ra mo-te-pe-ne?

$(*)$

Em estudo anterior (Mistieri, 2010: 20-21), foi realizada uma análise do acento da língua com base nas obras poéticas de Anchieta - via análise da estrutura métrica dos Poemas à Virgem, seguindo a metodologia de Massini-Cagliari (1999) - que ajuda a comprovar as afirmações anteriores. A metodologia utilizada neste estudo baseou-se nos trabalhos de Massini-Cagliari com o português arcaico. Segundo a linguista: 
"A única maneira de se estudar historicamente fenômenos como a acentuação e ritmo é através de textos poéticos metrificados, porque é somente a estrutura métrica dos versos que pode fornecer pistas a respeito da estrutura prosódica (aí incluída a estrutura métrica) de palavras de uma época da língua (ou de uma língua já não mais falada) que se conhece apenas através de textos escritos. Neste sentido, o estudo da estruturação rítmica dos versos (número de sílabas poéticas, posição do acento) faz-se imprescindível, porque pode fornecer pistas da localização do acento em palavras já em desuso e em vocábulos desconhecidos." (Massini-Cagliari, 1995: 181).

Dos poemas que foram analisados sob a utilização da metodologia dos versos-chave, foram encontradas 366 palavras diferentes em posição de rima, dentre as quais 217 eram paroxítonas $(59,29 \%), 146$ oxítonas $(39,89 \%)$ e 3 monossílabos tônicos $(0,82 \%)$. No caso das paroxítonas, identificou-se que todas as palavras possuem terminações em $-a,-i,-m o,-b o,-p e,-n e,-m e,-u$. Todas elas estavam previstas como átonas por Lemos Barbosa (1956) e por Cardoso em adendo à edição de 1990 de Artes de gramática da língua mais usada na costa do Brasil (escrita originalmente por Anchieta no final do século XVI). A saber:

$\{-a\}$ - Caso nuclear, também conhecido como sufixo nominalizador, que tem como função transformar uma cláusula verbal finita em um sintagma nominal. Este sufixo se apresenta em diversas línguas da família.

$\{$-ne $\}$ Partícula expletiva, afirmativa de realce

$\{$-mo\} e $\{$-bo $\}$ - sufixos indicativos de gerúndio

$\{$-pe $\}$ - sufixo indicativo de locativo

$\{-\mathrm{i}\}$ e $\{-\mathrm{u}\}$ - expressam modo indicativo circunstancial

$\{$-me $\}$ - indicativo de oração subordinada adverbial

Não foram encontradas ocorrências de paroxítonas que não possuíssem algum tipo de sufixação.

Esta constatação somente endossa a tese de que a língua leva em consideração aspectos morfológicos ao estabelecer padrões acentuais, em detrimento das características fonológicas.

\section{Outra aplicação da metologia desenvolvida}

A metodologia desenvolvida foi utilizada também já em outro trabalho acadêmico. Abreu (2012), em sua dissertação de mestrado, para a análise de vários dados, lança mão do conceito de 'verso-chave'. A autora, com relação a sílabas tônicas de palavras fora da posição de rima, lança mão de tal metodologia:

Para sabermos se há mais alguma proeminência em vellocinna, 
recorremos a outro verso da mesma cantiga, o qual denominamos de "verso-chave" (cf. Mistieri, 2010), ou seja, um verso que nos guia na marcação das outras sílabas tônicas dos demais versos da cantiga. Tal verso é o seguinte: "mui/ ca/ti/va/ e/ mui/ po/bre". Este verso foi escolhido pois, tomando como base Mistieri (2010), nele não ocorre nenhum tipo de ditongação ou encontro vocálico intervocabular que possa deixar dúvida quanto à sua divisão silábica e, consequentemente, à atribuição de acentos poéticos. (ABREU, 2012: 146)

Seu estudo focalizava as formas aumentativas e diminutivas em Português Arcaico, discutindo questões prosódicas relacionadas a elas, a partir das Cantigas de Santa Maria e de cantigas profanas medievais. Para tanto, utilizou a metodologia proposta por Massini-Cagliari $(1995,2005)$ no estudo de fenômenos prosódicos em textos poéticos antigos. Essa metodologiaé precursora dos estudos nessa área e tem motivado diversas pesquisas, principalmente sobre o Português Arcaico.

\section{Conclusão}

Nossa pesquisa abordou o acento em Tupi Antigo, apresentando evidências da escrita de textos poéticos de Anchieta para a análise. Acrescentamos a metodologia do 'verso-chave' à abordagem adotada por Massini-Cagliari e membros de seu grupo de pesquisa, no estudo da prosódia via textos antigos metrificados.

É curioso observar os caminhos que objetos de estudo e pesquisas a eles relacionadas tomaram. A lírica medieval portuguesa, com toda sua tradição de métrica, influenciou a produção do Padre Anchieta, que, apesar de fiel a essa tradição de se construir versos, como dissemos anteriormente, não forçou a língua Tupi na métrica. Observa-se que, diante das escolhas lexicais, ele teceu os poemas com a métrica exigida, mas adequada aos padrões acentuais do Tupi. O mesmo Massini-Cagliari e pesquisadores têm dito sobre o Português Arcaico: a métrica adequou-se à língua e não o contrário.

Seguramente, a tradição ibérica de poemas à Virgem Maria, como as Cantigas de Santa Maria, do Rei Afonso X, estudadas por Massini-Cagliari, influenciou a produção de poemas à Virgem de Anchieta. Ele os escreveu em parte em Tupi, mostrando que qualquer língua pode expressar qualquer pensamento, e pode produzir obras literárias sob qualquer padrão estético.

Vemos que a influência ibérica propiciou o surgimento dos poemas em Tupi, que passamos a analisar. E temos então o Português influenciando a compreensão do Tupi. Mas, séculos depois de Anchieta, nossa proposta metodológica de análise de versos-chave influenciou a análise de versos de Cantigas de Santa Maria. Então temos o Tupi influenciando a compreensão do Português. 


\section{Referências}

Abreu, T. H. 2012. Estudo das formas aumentativas e diminutivas em português arcaico. 211p. Dissertação (Mestrado em Linguística e Língua Portuguesa) - Universidade Estadual Paulista, Faculdade de Ciências e Letras, Araraquara.

Anchieta, J. 1954. Poesias, transcrições, traduções e notas de Maria de Lourdes de Paula Martins. Boletim IV, Museu Paulista - Documentação Lingüística, 4, São Paulo.

1984. Língua Portuguesa e Tupi, organizado por Pe. Armando Cardoso. São Paulo: Edições Loyola.

. 2004.Poemas - Lírica Portuguesa e Tupi, organizado por Eduardo de Almeida Navarro. Martins Fontes, São Paulo.

. 1990. Artes de gramática da língua mais usada na costa do Brasil . Transliteração e notas Pe. Armando Cardoso. São Paulo: Loyola, p. 21 (ed. fac-símile).

Barbosa, A. L. 1956. Curso de Tupi Antigo. Rio de Janeiro: Livraria São José.

Costa, D. S. 2010. A interface música e linguística como instrumental metodológico para o estudo da prosódia do português arcaico. 200p. Tese (Doutorado em Linguística e Língua Portuguesa) - Universidade Estadual Paulista, Faculdade de Ciências e Letras, Araraquara.

2006. da Estudo do acento lexical no português arcaico por meio das Cantigas de Santa Maria. 163p. Dissertação (Mestrado em LingUística e Língua Portuguesa) Universidade Estadual Paulista, Faculdade de Ciências e Letras, Araraquara.

Hayes, B. 1995. Metrical Stress Theory: Principles and Case Studies. Chicago, London: University of Chicago Press.

Hogg, R; Mccully, C.B. 1987. Metrical Phonology: a coursebook. New York: Cambridge University Press.

Hooper, J. 1976. An Introduction to Natural Generative Phonology. New York: Academic Press.

Kahn, D. 1976. Syllable - based generalizations in English Phonology. Department of Linguistics, MIT, Cambridge (Doctoral Dissertation).

Liberman, M. \& Prince, A..1977. On stress and linguistc rhythm. Linguistic Inquiry, Cambridge, MA., n. 8, p. 249-336.

Massini-Cagliari, Gladis. 2005. A música da fala dos trovadores. Estudos de Prosódia do Português Arcaico, a partir das cantigas profanas e religiosas. 348f. Tese (Livre Docência em Linguística e Língua Portuguesa) - Faculdade de Ciências e Letras, Universidade Estadual Paulista "Júlio de Mesquita Filho", Araraquara. . 1999. Do poético ao lingüístico no ritmo dos trovadores: três momentos na história do acento. Araraquara: Laboratório Editorial FCLAr. 
1995. Cantiga de Amigo: Do Ritmo Poético ao Lingüístico - Um Estudo do Percurso Histórico da Acentuação do Português. 269p. Tese (Doutorado em Linguística) Universidade Estadual de Campinas, Instituto de Estudos da Linguagem.

Mistieri, Fernanda Regina. 2013. Acento em línguas Tupi-Guarani: uma análise comparada. 123p. Dissertação (Mestrado) - Faculdade de Filosofia, Ciências e Letras - Universidade Estadual Paulista, Araraquara.

. 2010. O acento em tupi antigo. Monografia de Conclusão de Curso (Letras) Faculdade de Ciências e Letras, Universidade Estadual Paulista “Júlio de Mesquita Filho", Araraquara.

Rodrigues, A. D. 1958. Phonologie der Tupinambá-Sprache, (tese de doutorado), Hamburgo.

."Relações internas na família linguística Tupi-guarani”. 1985. In: Revista de Antropologia (Separata das edições 27 e 28). São Paulo: Universidade de São Paulo.

Recebido em 5 de maio de 2016

Aceito em 20 de maio de 2016 